\title{
The blue vibronically resolved electroluminescence of azatrioxa[8]circulene
}

\author{
Valiev, R. R.
}

2019-10

Valiev, R R , Gadirov , R M , Degtyarenko, K M , Grigoryev , D , Nasubullin , R T, Baryshnikov, G , Minaev , B F , Pederse , S K \& Pittelkow , M 2019 , ' The blue vibronically resolved electroluminescence of azatrioxa[8]circulene ' , Chemical Physics Letters, vol. 732 , 136667 . https://doi.org/10.1016/j.cplett.2019.136667

http://hdl.handle.net/10138/333160

https://doi.org/10.1016/j.cplett.2019.136667

cc_by_nc_nd

acceptedVersion

Downloaded from Helda, University of Helsinki institutional repository.

This is an electronic reprint of the original article.

This reprint may differ from the original in pagination and typographic detail.

Please cite the original version. 


\title{
The Blue Vibronically Resolved Electroluminescence of Azatrioxa[8]circulene
}

R.R. Valiev ${ }^{1,2}$, R.M. Gadirov ${ }^{1}$, K.M. Degtyarenko ${ }^{1}$, D.V. Grigoryev ${ }^{1}$, R.T. Nasubullin ${ }^{1}$, G.V. Baryshnikov ${ }^{1}$, B. F. Minaev ${ }^{3}$, S.K. Pedersen ${ }^{4}$, M. Pittelkow ${ }^{4}$

${ }^{1}$ Tomsk State University, 36 Lenin Avenue, Tomsk, 634050, Russia

${ }^{2}$ University of Helsinki, Department of Chemistry, P.O. Box 55 (A.I. Virtanens plats 1), FIN-00014 University of Helsinki, Finland

${ }^{3}$ Department of Chemistry and Nanomaterials Science, Bohdan Khmelnytsky National University, 18031, Cherkasy, Ukraine

${ }^{4}$ Department of Chemistry, University of Copenhagen, Universitetsparken 5, DK-2100 Copenhagen, Denmark,

\begin{abstract}
Organic Light Emitting Dioides (OLED )devices were fabricated with blue emission based on azatrioxa[8]circulene and 4,4-N,N'-Dicarbazolyl-1,1'-biphenyl (CBP) with maximum brightness of $840 \mathrm{kd} / \mathrm{m}^{2}$ at $12 \mathrm{~V}$ and the starting voltage of $3.5 \mathrm{~V}$. The vibronic emission spectrum was analyzed by the promotive modes calculation method. The electroluminescence of fabricated OLED device is caused by the 0-0 electronic transition and single excitations of $1473 \mathrm{~cm}^{-1}$ and $1673 \mathrm{~cm}^{-1}$ modes and combinations thereof.
\end{abstract}

\section{Keywords}

organic light emitting device, transition electroluminescence, vibronic spectra, blue emission.

\section{Introduction}

At present, organic light-emitting diode (OLED) technology is starting to dominate the market of displays for consumer electronics. This is due to the fact that manufacturing technology of OLED displays is cheaper than that of liquid crystal display (LCD) matrices [1]. Usually, OLED displays utilize classical (red, green, and blue) scheme. While the technology of red and green OLEDs is almost brought to perfection, the development of stable and efficient blue-emitting OLEDs is still problematic [1]. Hence, the search of thermally and chemically stable substances emitting in the blue region of the spectrum is an urgent challenge for OLED technology.

Among organic compounds suitable for use as OLED materials, hetero[8]circulenes have emerged in the past decade as a promising choice [2]. They exhibit high thermal and chemical stability and emit blue light. In 2016, we predicted theoretically the photophysical properties of a series of hetero[8]circulenes [3]. Azatrioxa[8]circulene (ATOC), which exhibits a high 
fluorescence quantum yield (0.9) was found to be among the most promising candidates for use as the blue component in OLEDs. Its structure is shown in Figure 1. The synthesis of ATOC was reported in 2015 [4], and in 2017 year it was used in circulene-based hybrid OLEDs [5]. It was noted that the fluorescence of solid ATOC was due to its own blue emission as well as excimer emission. Therefore, the fluorescence of pure ATOC is not pure blue.

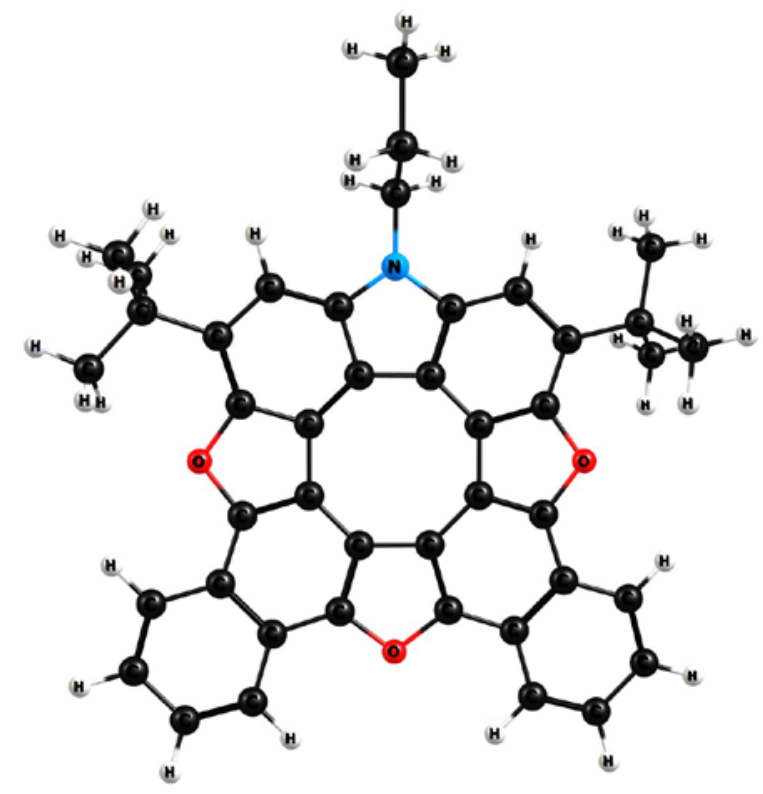

Figure 1. The equilibrium geometry of electronic ground state of ATOC.

In this work we present an OLED based on ATOC and 4,4-N,N'-Dicarbazolyl-1,1'biphenyl (CBP) fabricated by physical vapor deposition. The device efficiently emits blue light. In addition, we present the brightness-voltage and current-voltage curves of the fabricated OLED and estimated its charge carrier mobility. We also present the simulated vibronic emission spectrum of ATOC within the Franck-Condon approximation.

\section{Experimental and Computational Details}

\section{Fabrication of OLED and measurement of its properties}

To study the electroluminescence characteristics, we fabricated the following OLED device: ITO/PEDOT:PSS (30 nm)/CBP (10 nm)/CBP:ATOC (20 nm)/BCP (10 nm)/LiF (1 $\mathrm{nm}$ )/Al (100 nm). Here 2,9-Dimethyl-4,7-diphenyl-1,10-phenanthroline (BCP) was used as holeblocking layer. Glass substrates with profiled ITO layer with resistance $12 \mathrm{Ohm} / \mathrm{square}$ were successively washed in hydrogen peroxide-ammonia solution with ultrasonication, acetone, and twice-distilled water, flushed with dry nitrogen, and treated with oxygen plasma. All the subsequent operations were performed in a glove box in dry nitrogen atmosphere. An aqueous suspension of PEDOT:PSS (Al4083 Ossila) was spin-coated at $2000 \mathrm{rpm}$ for $30 \mathrm{~s}$ and dried for $30 \mathrm{~min}$ at $110^{\circ} \mathrm{C}$. The organic layers of $\mathrm{CBP}$, ATOC, BCP, as well as $\mathrm{LiF}$ and $\mathrm{Al}$ were vapor 
deposited using the Auto 306 vacuum coater (BOC Edwards). ATOC was co-deposited with CBP at a ratio of 1 ATOC : $10 \mathrm{CBP}$. The deposition rate was below $0.3 \AA / \mathrm{s}$ for all organic layers. To prevent the exposure to atmosphere, the device was sealed with glass using UVcurable Encapsulation Epoxy (Ossila). The current-voltage and brightness-voltage curves as well as spectra were measured using an automated complex with the Keithley 237 source-measure unit and the AvaSpec-2048x64 CCD spectrometer (Avantes) with radiance calibration sphere AvaSphere-50-LS-HAL-CAL. The thicknesses of the deposited layers were measured with the MicroXAM-100 interferometer-based optical profiler (KLA Tenkor) using satellite substrates placed in an evaporation chamber holder together with the main sample.

The ATOC compound was synthesized according to the previously described procedure [4], and was purified by repeated column chromatography.

The charge carrier mobility was measured by transient electroluminescence method using the procedure described in detail in [6] with an apparatus consisting of the TDS224 oscillograph (Tektronix), an AWG-4105 arbitrary waveform oscillator (Aktakom), the FEU-35 photomultiplier, and an amplifier.

The equilibrium geometries of the electronic ground $\left(S_{0}\right)$ and the first excited singlet $\left(S_{1}\right)$ states of the molecule in this study were optimized at the time-dependent density functional theory (TDDFT) level [7] using B3LYP hybrid functional [8, 9] and the 6-31G(d,p) basis set [10].

The vibronic spectra were simulated within linear approximation, where the vibrational frequencies of the $S_{0}$ and $S_{1}$ states are assumed to be the same [11 - 19]. In this case, the activity of each mode can be characterized with its Huang-Rhys factors $(y)$. The latter can be found from the hessian of the initial state and the gradient of the final electronic state:

$$
y_{j}=\frac{1}{2} \omega_{j} \Delta Q_{j}^{2}=\left(V_{j}^{f}\right)^{2} / 2 \omega_{j}^{3}
$$

where $V_{j}^{, f}=\left.\partial E^{, f} \partial \partial Q_{j}\right|_{Q=Q_{0}}$ is the gradient of the potential energy surface along the $j$-th mode of the final electronic state $(f)$. Here $\omega_{j}$ and $Q_{j}$ are the frequency and normal coordinate of the $j$-th mode. The $\Delta Q_{j}$ is the displacement of the equilibrium position of the $j$-th oscillator. In this case the activity of each mode can be estimated using Franck-Condon factors $<0_{j} \mid n_{j}>^{2}=\frac{\exp \left(-y_{j}\right) y_{j}^{n_{j}}}{n_{j} !}$, and the transition dipole moment for the vertical excitation $(<i|\hat{d}| f>$ ) is the following:

$$
I_{j}=<i|\hat{d}| f>^{2} \cdot<0_{j} \mid n_{j}>^{2} .
$$


In this case we neglect the temperature effect and consider the limit of $\mathrm{T}=0 \mathrm{~K}$.

\section{Results and Discussion}

\section{The characteristic of OLED Devices}

Figure 2 shows the current-voltage and brightness-voltage curves of the fabricated OLED device, as well as the electroluminescence spectrum of the device at $10 \mathrm{~V}$.
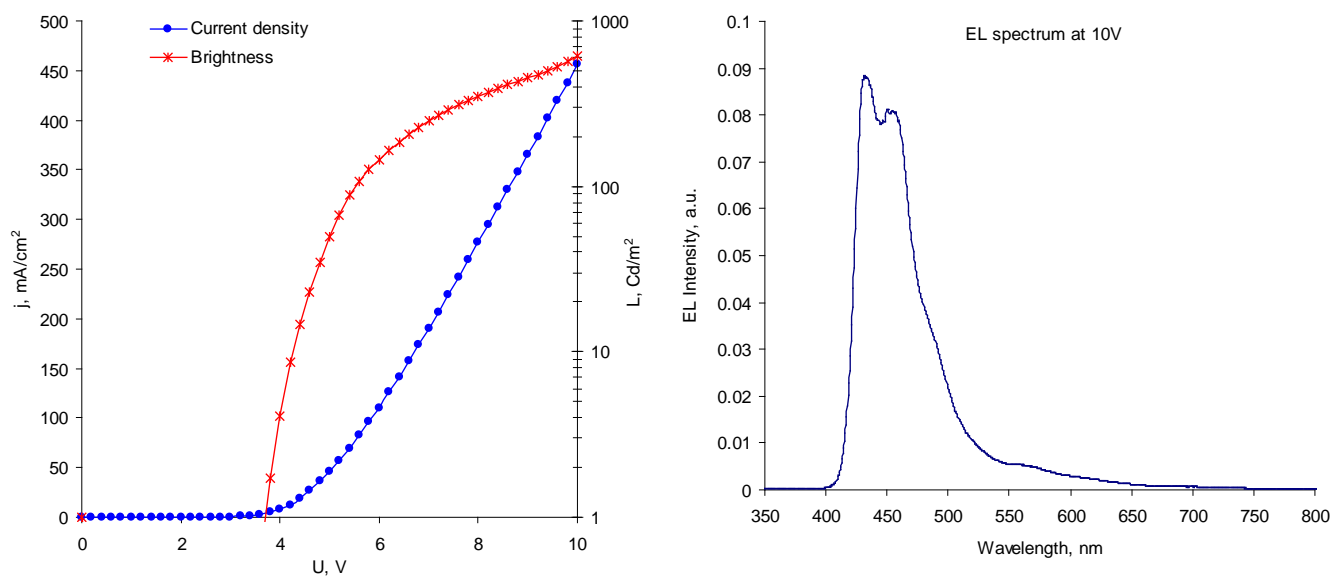

Figure 2. Current-voltage and brightness-voltage curves of the OLED and its electroluminescence spectrum at $10 \mathrm{~V}$.

At $10 \mathrm{~V}$ the brightness of the OLED device is $610 \mathrm{~cd} / \mathrm{m}^{2}$, which is acceptable for displays [20]. The maximum brightness at $12 \mathrm{~V}$ is $840 \mathrm{~cd} / \mathrm{m}^{2}$. The current efficiency is $0.133 \mathrm{~cd} / \mathrm{A}$. The starting voltage is $3.8 \mathrm{~V}$. The electroluminescence exhibits a pronounced vibronic progression, while the excimer band observed in devices fabricated in [5] is absent. Figure 3 shows the color temperature diagram. One can see from Figure 3 that $\mathrm{x}=0.168$ and $\mathrm{y}=0.101$ is near blue color approaching dark blue. 


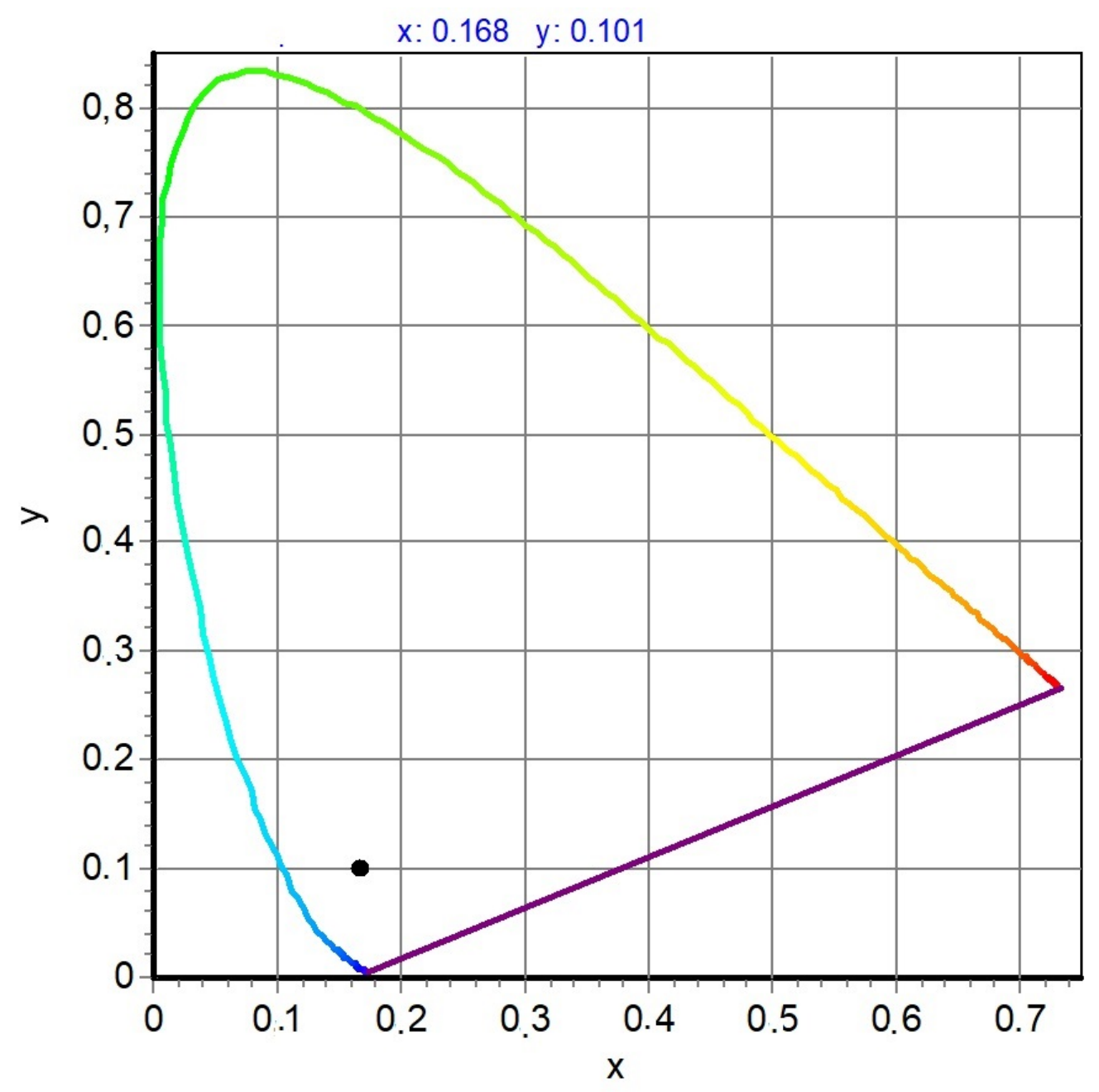

Figure 3. Color temperature diagram.

Figure 4 shows the charge carrier mobilities $\mu_{0.01}$ and $\mu_{0.5}$ as functions of the square root of the electric field $E$ measured by transient electroluminescence by the rise of the signal by $1 \%$ and $50 \%$, respectively. The mobility measured at $1 \%$ signal level corresponds to fast carriers that recombine first, and the mobility $\mu_{0.5}$ corresponds to the main body of the recombined charge carriers. Hence, the charge carrier mobility $\mu$ measured by transient electroluminescence is $10^{-}$ ${ }^{6} \mathrm{~cm}^{2} \mathrm{~V}^{-1} \mathrm{~s}^{-1}$. This value is much lower than those observed in tetrathio- and tetraseleno[8]circulene derivatives, where the charge carrier mobility reaches $9 \times 10^{-3} \mathrm{~cm}^{2} \mathrm{~V}^{-1} \mathrm{~s}^{-1}$ [21]. However, this agrees with the study of G.V. Baryshnikov [5] that low charge carrier mobility of azatrioxa[8]circulenes has only slight effect on the OLED device efficiency. Generally we conclude the parameters of the present OLED are comparable to the previously fabricated one based on the $\pi$-extended tetraoxa[8]circulenes, but the electroluminescence band is narrower and therefore it is more promising in blue OLED technology [22]. 


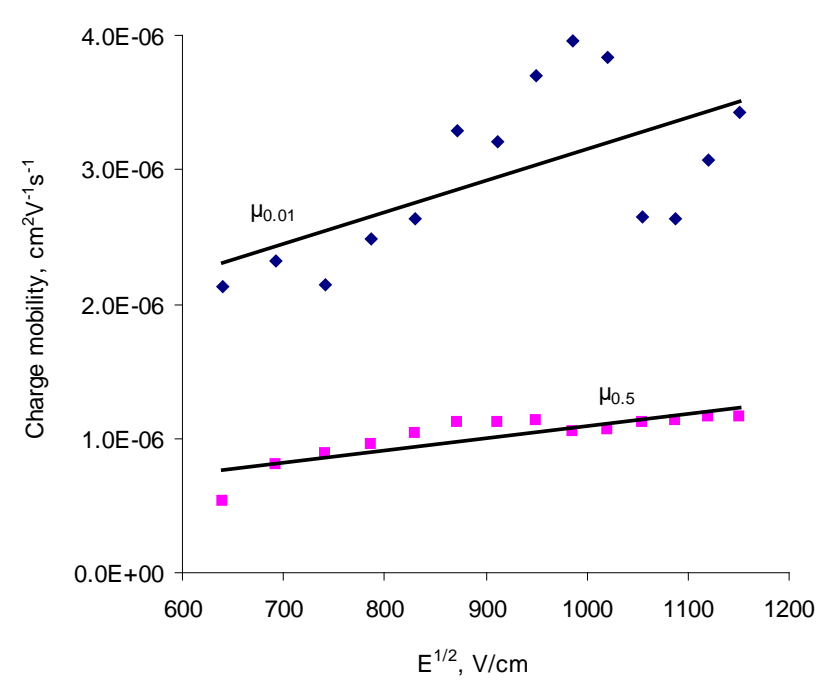

Figure 4. Charge carrier mobilities $\mu_{0.01}$ and $\mu_{0.5}$ as functions of the square root of the electric field $E$.

\section{Vibronic spectrum}

Figure 5 shows the simulated vibronic emission spectra of ATOC, and Figure 6 shows the promoting modes. One can see from Figure 6 that the modes $1673 \mathrm{~cm}^{-1}$ with $y=0.14$ and $1473 \mathrm{~cm}^{-1}$ with $y=0.07$ are promoting. The mode $1673 \mathrm{~cm}^{-1}$ is partially localized on the inner 8carbon cycle. In pure tetraoxa[8]circulene and azaoxa[8]circulene such mode with the frequency of $\sim 1700 \mathrm{~cm}^{-1}$ and $y>0.5$ is fully localized on the inner 8-carbon cycle [12, 19, 23]. Whereas in azatrioxa[8]circulene substituted with naphthalene moieties the intensity of this mode decreases since it is not fully localized anymore on the inner [8]-carbon cycle anymore. Refs. [12, 19] also mention that the presence of a vibration with the frequency of $\sim 1700 \mathrm{~cm}^{-1}$ and $y>0.5$ results in a large internal conversion rate constant $\left(k_{I C}\right)$.

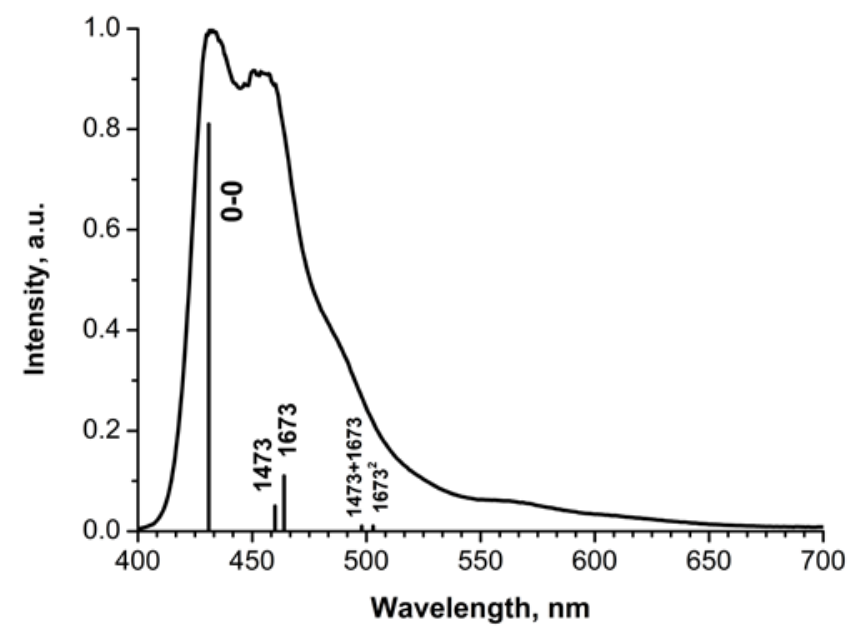

Figure 5. The experimental electroluminescence spectrum of the fabricated device of ATOC and the positions (nm) and intensities (a.u.) of calculated vibronic bands. 


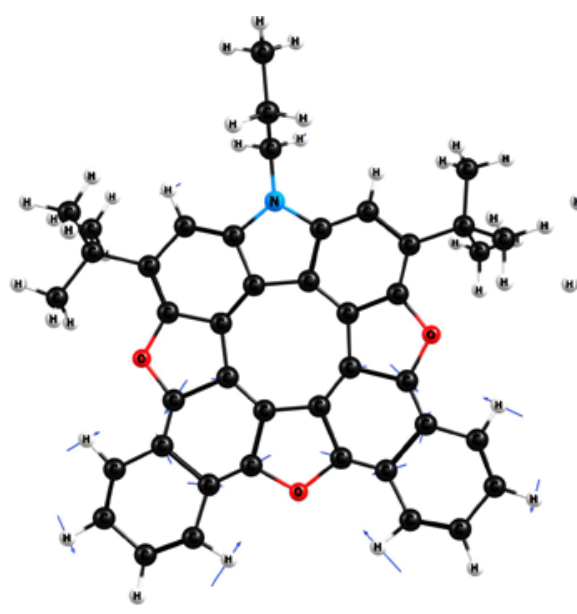

1473(0.07)

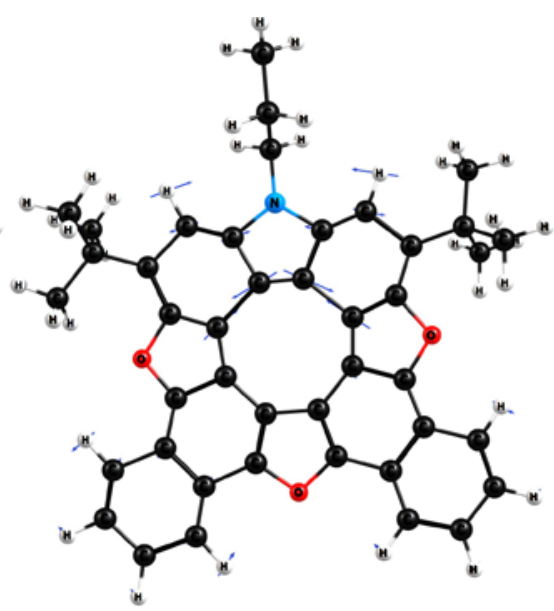

$1673(0.14)$

Figure 6. Promoting modes (in $\mathrm{cm}^{-1}$ ). The y values are given in parenthesis.

Therefore, reducing the $y$ value of this mode may reduce $k_{I C}$ as one of the nonradiative relaxation channels and, consequently, increase the fluorescence quantum yield. Table 1 gives the emission intensities $I_{j}$ for excitations to these particular modes and to the pure electronic transition (0-0).

Table 1. The calculated excitation of modes $\left(\mathrm{cm}^{-1}\right)$ and position of lines in the emission spectrum of ATOC.

\begin{tabular}{|c|c|}
\hline The type of excitation & Wavelength in $\mathrm{nm}$; intensity in a.u. \\
\hline $0-0$ & $431 \mathrm{~nm} ; 0.85$ \\
\hline $1473^{1}$ & $460 \mathrm{~nm} ; 0.05$ \\
\hline $1673^{1}$ & $464 \mathrm{~nm} ; 0.11$ \\
\hline $1673+1473$ & $498 \mathrm{~nm} ; 0.01$ \\
\hline $1673+1673$ & $503 \mathrm{~nm} ; 0.01$ \\
\hline
\end{tabular}

One can see from Table 1 that the first peak is a pure electronic 0-0 transition, and it is the most intense. The second peak is produced by single excitations of the two modes, $1473 \mathrm{~cm}^{-1}$ and $1673 \mathrm{~cm}^{-1}$. A small shoulder at $498-500 \mathrm{~nm}$ is determined by overtones: single excitations of the modes $1473 \mathrm{~cm}^{-1}$ and $1673 \mathrm{~cm}^{-1}$ and a double excitation of mode $1673 \mathrm{~cm}^{-1}$. Hence, the electroluminescence of the fabricated OLEDs based on ATOC and CBP originates from the 0-0 transition of ATOC and its vibronic progression. The ATOC itself in a solid phase produces a strong excimer shoulder at $550 \mathrm{~nm}$; as a consequence solid ATOC can not provide blue emission. But if the ATOC is introduced into the matrix - excimers are not formed and the device produces the proper blur color. The absence of the excimer band in the 
electroluminescence spectrum at $600 \mathrm{~nm}$ [5], which was observed in the case of pure ATOCbased OLED, results finally in a desirable blue emission. Therefore, we have identified the origin of electroluminescence of the fabricated OLED device.

\section{Conclusions}

Efficient OLED devices have been fabricated with blue emission based on azatrioxa[8]circulene and CBP. The maximum brightness is $840 \mathrm{kd} / \mathrm{m}^{2}$ at $12 \mathrm{~V}$ and the starting voltage is of $3.5 \mathrm{~V}$. It can be used in the fabrication of B layer in RGB display for the gadgets due to the high chemical and thermal stability of azatrioxa[8]circulene [2]. It was shown that the electroluminescence of fabricated OLED device is caused by the 0-0 electronic transition and single excitations of $1473 \mathrm{~cm}^{-1}$ and $1673 \mathrm{~cm}^{-1}$ modes and their combination. Although the electroluminescence color is not pure dark blue, further structural modification by substitution will make it possible to reduce the intensity of the $1673 \mathrm{~cm}^{-1}$ vibronic peak, because it is localized mainly inside the ATOC macrocycle [3]. This may result in a narrower electroluminescence band originating from the $0-0$ electronic transition at $431 \mathrm{~nm}$. One can note that present study supports the general trend about photophysical properties of hetero[8]circulene being correlate with their aromaticity [2-5,24].

\section{Acknowledgments}

The research was carried out at the expense of the grant from Russian Science Foundation (project No. 17-73-20012).

\section{References}

[1] R. P. Xu, Y. Q. Li and J. X. Tang, Recent advances in flexible organic light-emitting diodes, J. Mater. Chem. C 4 (2016) 9116-9142. https://doi.org/10.1039/C6TC03230C

[2] N. N. Karaush, G. V. Baryshnikov, V. A. Minaeva, H. Ågren and B. F. Minaev, Recent progress in quantum chemistry of hetero[8]circulenes, Mol. Phys. 115 (2017) 2218-2230. https://doi.org/10.1080/00268976.2017.1287438

[3] G. V. Baryshnikov, R. R. Valiev, N. N. Karaush, V. A. Minaeva, A. N. Sinelnikov, S. K. Pedersen, M. Pittelkow, B. F. Minaev, H. Agren, Benzoannelated aza-, oxa- and azaoxa[8]circulenes as promising blue organic emitters, Phys. Chem. Chem. Phys. 18 (2016) 28040-28051. https://doi.org/10.1039/C6CP03060B

[4] M. Plesner, T. Hensel, B. E. Nielsen, F. S. Kamounah, T. BrockNannestad, C. B. Nielsen, C. G. Tortzen, O. Hammerich, M. Pittelkow, Synthesis and properties of unsymmetrical azatrioxa[8]circulenes, Org. Biomol. Chem. 13 (2015) 5937. https://doi.org/10.1039/c5ob00676g 
[5] K. B. Ivaniuk, G. V. Baryshnikov, P. Y. Stakhira, S. K. Pedersen, M. Pittelkow, A. Lazauskas, D. Volyniuk, J. V. Grazulevicius, B. F. Minaev and H. Ågren, New WOLEDs based on p-extended azatrioxa[8]circulenes, J. Mater. Chem. C 5 (2017) 4123-4128. https://doi.org/10.1039/c7tc00655a

[6] I. V. Romanov, V. Voitsekhovskii, K. M. Dyagterenko, T. N. Kopylova, A. P. Kokhanenko, E. N. Nikonova, Measurement of the Charge Carrier Mobility in MEH-PPV and MEH-PPV-POSS Organic Semiconductor Films, Russ. Phys. J. 57 (2015) 1584. https://doi.org/10.1007/s1118

[7] M. E. Casida, Time-Dependent Density Functional Response Theory for Molecules, in: Recent advances in Density-Functional Methods Part I, World Scientific: Singapore, 1999, pp. 155-192.

[8] A. D. Becke, Density functional thermochemistry. III. The role of exact exchange, J. Chem. Phys. 98 (1993) 5648. https://doi.org/10.1063/1.464913

[9] C. Lee, W. Yang, R.G. Parr, Development of the Colle-Salvetti correlation-energy formula into a functional of the electron density, Phys. Rev. B 37 (2) (1988) 785. https://doi.org/10.1103/PhysRevB.37.785

[10] V.A. Rassolov, J.A. Pople, M.A. Ratner, T.L. Windus, 6-31G* basis set for atoms K through Zn, J. Chem. Phys. 109 (4) (1998) 1223-1229. https://doi.org/10.1063/1.476673.

[11] A. Ya. Freidzon, R. R. Valiev, A. A. Berezhnoy Ab Initio Simulation of Pyrene Spectra in Water Matrices, RSC Adv. 4 (2014) 42054-42065. https://doi.org/10.1039/c4ra05574h

[12] R. R. Valiev, V. N. Cherepanov, G. V. Baryshnikov and D. Sundholm, Firstprinciples method for calculating the rate constants of internal-conversion and intersystemcrossing transitions. Phys. Chem. Chem. Phys. 20(9) (2018) 6121-6133. https://doi.org/10.1039/C7CP08703A

[13] M. Lax, The Franck-Condon Principle and Its Application to Crystals, J. Chem. Phys., 20 (1952) 1752. https://doi.org/10.1063/1.1700283

[14] E. J. Heller, The semiclassical way to molecular spectroscopy, Acc. Chem. Res. 14 (12) (1981) 368-375. https://doi.org/10.1021/ar00072a002

[15] G. V. Baryshnikov, R. R. Valiev, V. N. Cherepanov, N. N. Karaush-Karmazin, V. A. Minaeva, B. F. Minaev and H. Ågren, Aromaticity and photophysics of tetrasila- and tetragermaannelated tetrathienylenes as new representatives of the hetero[8]circulene family, Phys. Chem. Chem. Phys. 21 (2019) 9246-9254 https://doi.org/10.1039/C9CP01608B 
[16] P. V. Yurenev, M. K. Kretov, A. V. Scherbinin and N. F. Stepanov, Environmental broadening of the CTTS bands: the hexaammineruthenium (II) complex in aqueous solution, J. Phys. Chem. A 114 (2010) 12804-12816. https://doi.org/10.1021/jp1031477

[17] M. K. Kretov, I.M. Iskandarova, B. V. Potapkin, A.V. Scherbinin, A. M. Srivastava and N. F. Stepanov, Simulation of structured $4 \mathrm{~T} 1 \rightarrow 6 \mathrm{~A} 1$ emission bands of $\mathrm{Mn}^{2+}$ impurity in $\mathrm{Zn}_{2} \mathrm{SiO}_{4}: \quad$ A first-principle methodology, J. Lumin. $132 \quad$ (2012) 2143-2150. https://doi.org/10.1016/j.jlumin.2012.03.067

[18] M. K. Kretov, A. V. Scherbinin and N. F. Stepanov, Simulating the structureless emission bands of $\mathrm{Mn}^{2+}$ ions in $\mathrm{ZnCO}_{3}$ and $\mathrm{CaCO}_{3}$ matrices by means of quantum chemistry, Russ. J. Phys. Chem. A 87 (2013) 245-251. https://doi.org/10.1134/S0036024413020179

[19] R. R. Valiev, V. N. Cherepanov, R. T. Nasibullin, D. Sundholm and T. Kurten, Calculating rate constants for intersystem crossing and internal conversion in the Franck-Condon and Herzberg-Teller approximations, Phys. Chem. Chem. Phys., (2019), DOI 10.1039/С9СР03183А.

[20] B. Minaev, G. Baryshnikov and H. Agren, Principles of phosphorescent organic light emitting devices, Phys. Chem. Chem. Phys. 16 (2014) 1719-1758. https://doi.org/10.1039/C3CP53806K

[21] A. Dadvand, F. Cicoira, K. Y. Chernichenko, E. S. Balenkova, R. M. Osuna, F. Rosei, V. G. Nenajdenko, D. F. Perepichka, Heterocirculenes as a new class of organic semiconductors, Chem. Commun. 42 (2008) 5354-5356. https://doi.org/10.1039/b809259a

[22] C. B. Nielsen, T. Brock-Nannestad, T. K. Reenberg, P. Hammershøj, J. B. Christensen, J. W. Stouwdam, and M. Pittelkow, Organic Light-Emitting Diodes from Symmetrical and Unsymmetrical $\pi$-Extended Tetraoxa [8] circulenes, Chem. Eur. J. 16 (44) (2010) 13030-13034. https://doi.org/10.1002/chem.201002261

[23] N. N. Karaush, R. R. Valiev, G. V. Baryshnikov, B. F. Minaev, H. Ågren, DFT simulation of the heteroannelated octatetraenes vibronic spectra with the Franck-Condon and Herzberg-Teller approaches including Duschinsky effect, Chem. Phys. 459 (2015) 65-71. https://doi.org/10.1016/j.chemphys.2015.08.003

[24] G. V. Baryshnikov, B. F. Minaev, M. Pittelkow, C.B. Nielsen and R. Salcedo, Nuclear independent chemical shift criterion for aromaticity in pi-extendedtetraoxa[8]circulene. J. Mol. Model. 19 (2013), 19, 847-850. https://doi.org/10.1007/s00894-012-1617-7 